\title{
The Aden Crater Lava Flows, Dona Ana Co., New Mexico
}
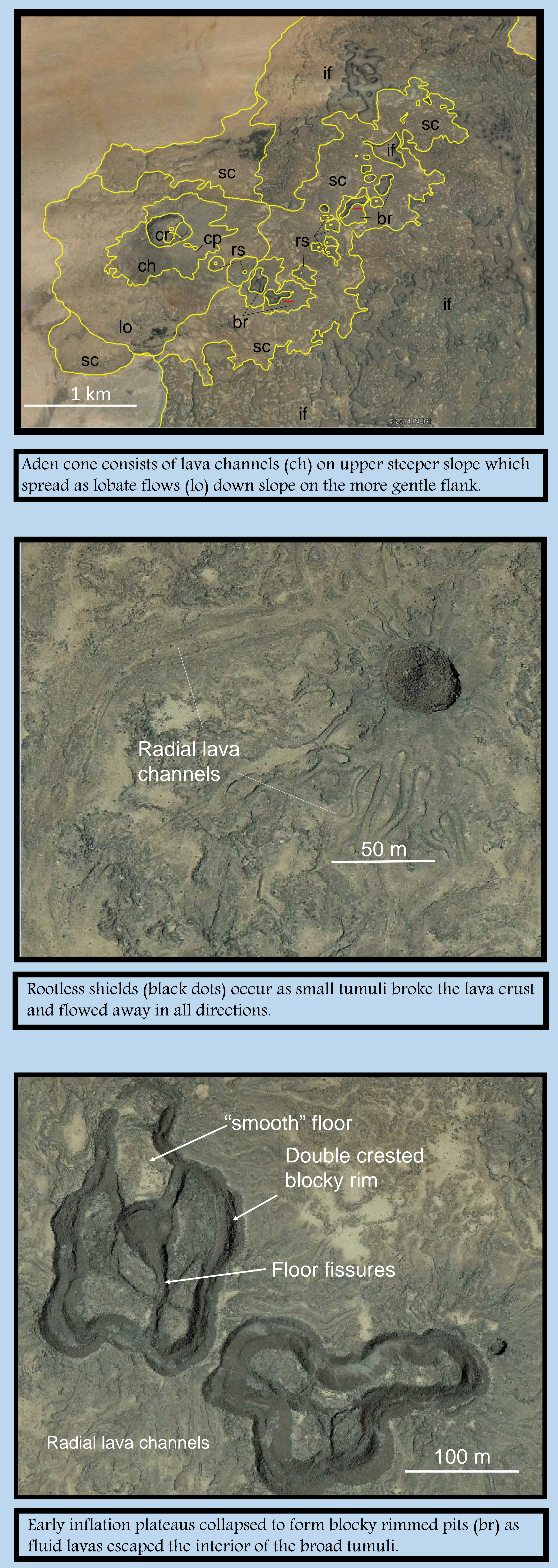

R. A. De Hon and R. A. Earl Department of Geography Texas State University

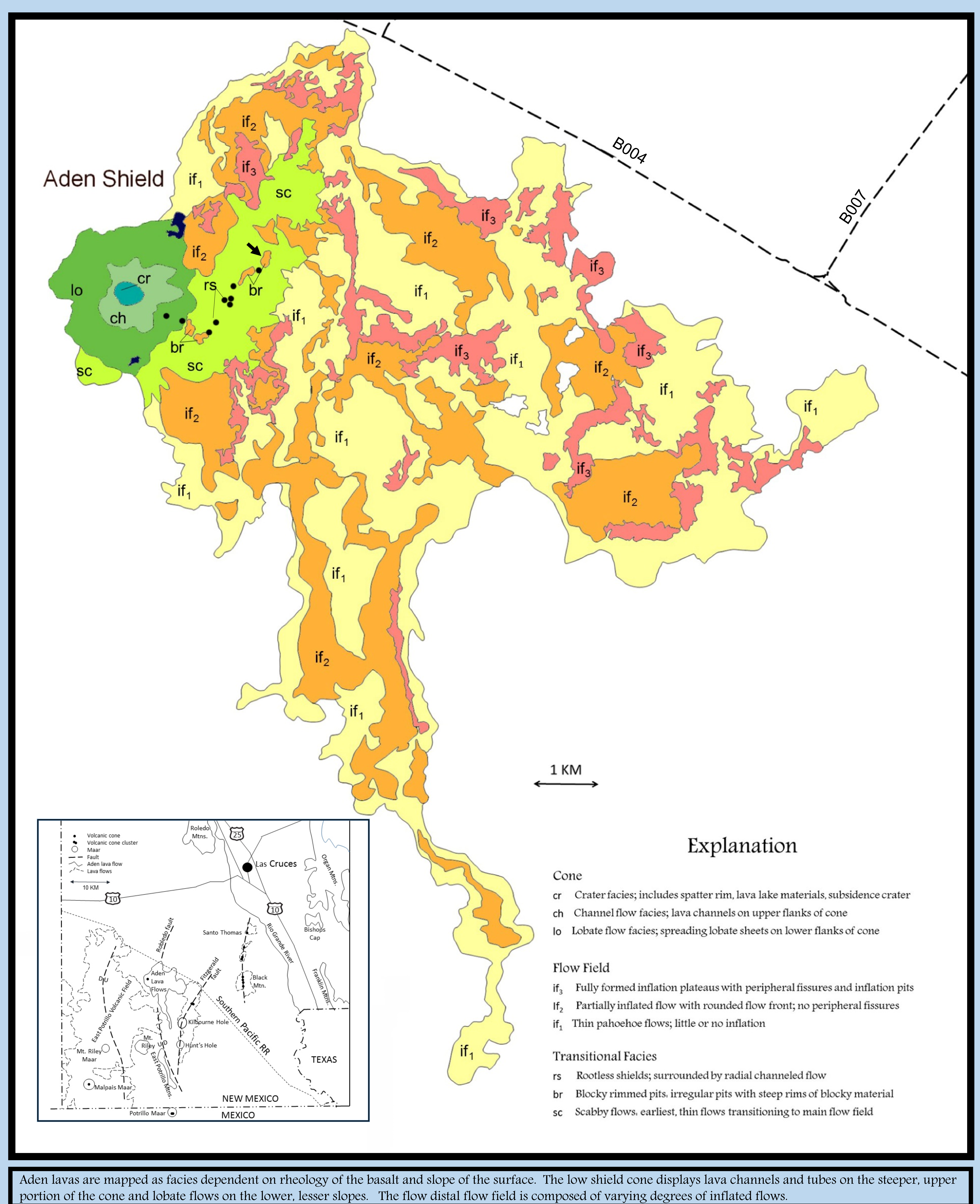

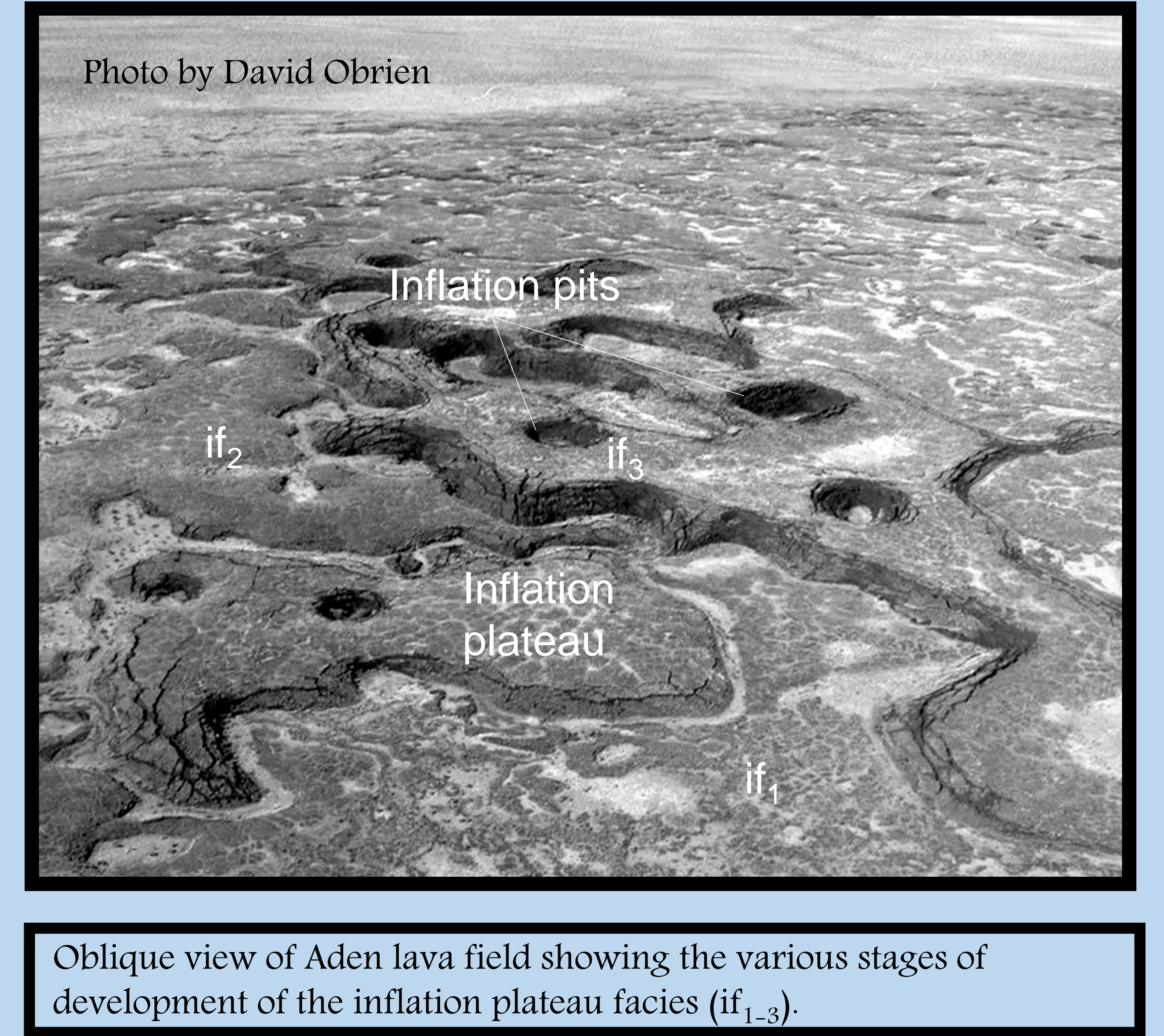
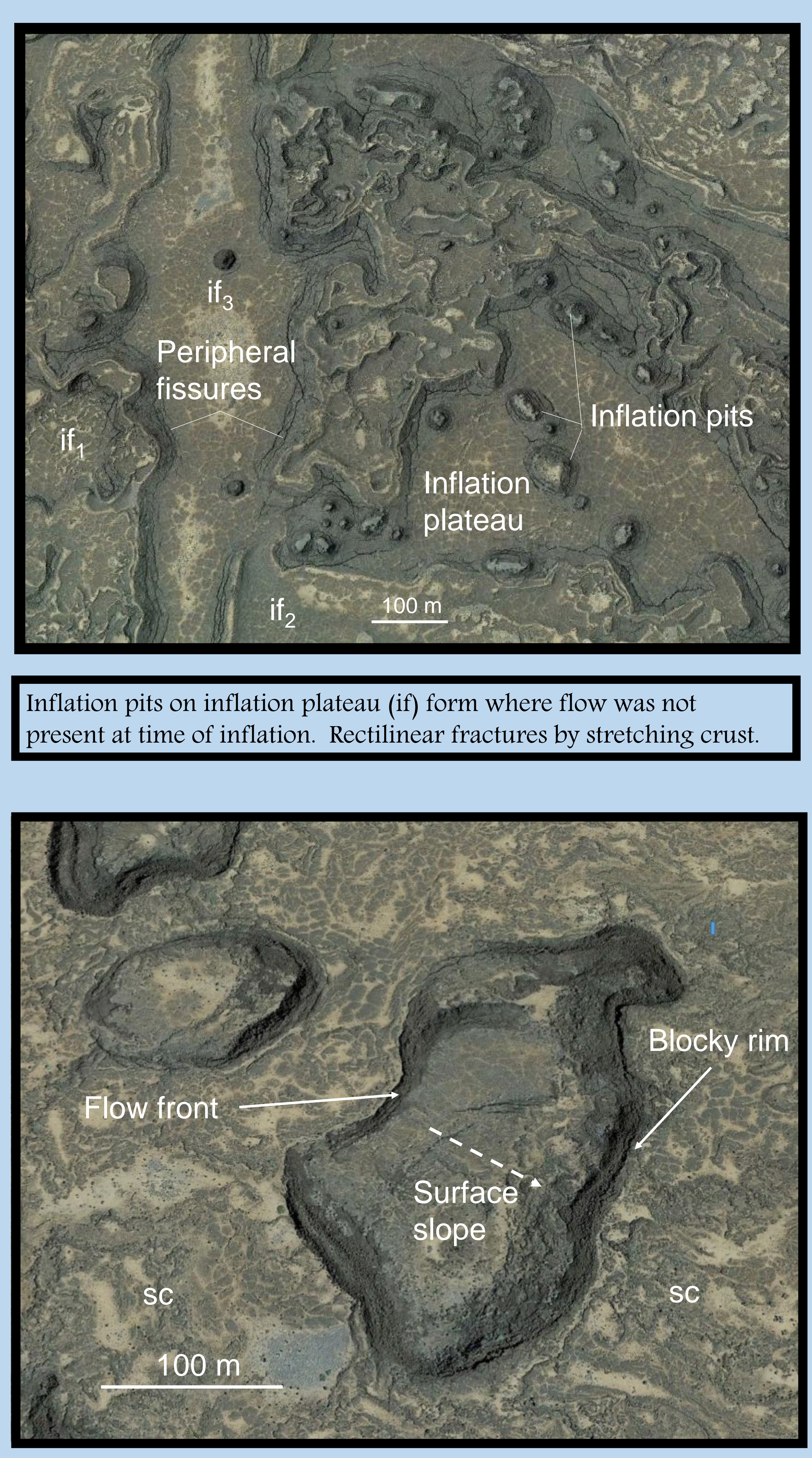

Partially collapsed inflation plateau (see arrow on facies map) exhibits 